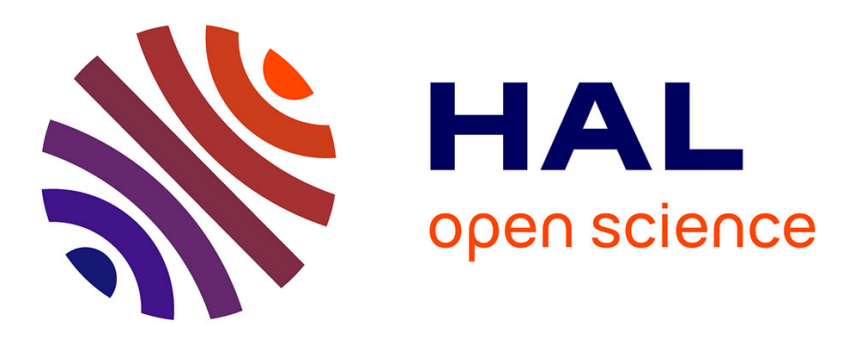

\title{
Effect of phosphorous-modified silica on the flame retardancy of polybutylene terephthalate based nanocomposites
}

Julie Courtat, Flavien Mélis, Jean-Marie Taulemesse, Véronique

Bounor-Legaré, Rodolphe Sonnier, Laurent Ferry, Philippe Cassagnau

\section{To cite this version:}

Julie Courtat, Flavien Mélis, Jean-Marie Taulemesse, Véronique Bounor-Legaré, Rodolphe Sonnier, et al.. Effect of phosphorous-modified silica on the flame retardancy of polybutylene terephthalate based nanocomposites. Polymer Degradation and Stability, 2017, 143, pp.74 - 84 . 10.1016/j.polymdegradstab.2017.06.014 . hal-01649973

\section{HAL Id: hal-01649973 https://hal.science/hal-01649973}

Submitted on 3 Jun 2021

HAL is a multi-disciplinary open access archive for the deposit and dissemination of scientific research documents, whether they are published or not. The documents may come from teaching and research institutions in France or abroad, or from public or private research centers.
L'archive ouverte pluridisciplinaire HAL, est destinée au dépôt et à la diffusion de documents scientifiques de niveau recherche, publiés ou non, émanant des établissements d'enseignement et de recherche français ou étrangers, des laboratoires publics ou privés. 


\title{
Effect of phosphorous-modified silica on the flame retardancy of polybutylene terephthalate based nanocomposites
}

\author{
Julie Courtat ${ }^{\mathrm{a}}$, Flavien Mélis ${ }^{\mathrm{a}}$, Jean-Marie Taulemesse ${ }^{\mathrm{b}}$, Véronique Bounor-Legaré ${ }^{\mathrm{a}}$, \\ Rodolphe Sonnier $^{\text {b }}$, Laurent Ferry ${ }^{\text {b, *, }}$ Philippe Cassagnau ${ }^{\text {a }}$ \\ a Université de Lyon, Université Lyon 1, UMR CNRS 5223, Ingénierie des Matériaux Polymères, Lyon F-6922, France \\ ${ }^{\mathrm{b}}$ Centre des Matériaux des Mines d'Alès (C2MA), Ecole des Mines d'Alès, 6 avenue de Clavières, 30319 Alès Cedex, France
}

\begin{abstract}
A B S T R A C T
The effect of silica treatment by three phosphorous compounds (phosphoric acid, dihydrogen ammonium phosphate and diammonium phosphate) on the thermal and fire behaviour of polybutylene terephthalate (PBT) composites was investigated using Thermogravimetric analysis (TGA), Pyrolysis Combustion Flow Calorimeter (PCFC) and cone calorimeter. It was found that with only $10 \mathrm{wt} \%$ of treated silica incorporated into PBT, which corresponds to only $0.2 \mathrm{wt} \%$ of phosphorus in composites, the fire behaviour of materials was dramatically improved with a $60 \%$ decrease of peak of Heat Release Rate (pHRR). The incorporation of modified silica also leads to a fire growth rate index of $4.3 \mathrm{~kW} /\left(\mathrm{m}^{2} . \mathrm{s}\right)$ (i.e. a $40 \%$ decrease). Those phenomena were related to the expansion of composites during their combustion and to their rheological behaviour. Indeed, the higher the viscosity at low frequencies is, the better the fire behaviour is, due to the induced barrier effect. A decrease of time to ignition (TTI) was also observed with the addition of the various silicas (up to $18 \mathrm{~s}$ with $10 \mathrm{wt} \%$ of neat silica), which was explained by the appearance of bubbles after the PBT melting during cone calorimeter tests leading to a fast increase of the surface temperature.
\end{abstract}

Keywords:

Silica

Phosphorous treatment

PBT

Rheology

Flame retardancy

\section{Introduction}

Polybutylene terephthalate (PBT) is an engineering thermoplastic polymer which exhibits very good heat resistance and electrical insulation properties. Thus PBT is an interesting solution for a wide range of industrial applications such as automotive parts, connectors for electronics, electrical components, cable jackets ... Many of these applications dictate stringent specifications with regard to reaction-to-fire and require PBT to be flame retarded.

Historically, flame retardancy of PBT was achieved by using halogenated compounds such as brominated carbonate, brominated polystyrene or brominated phosphate ester [1,2]. From the early 2000s and notably due to the restriction of some hazardous substances in electrical and electronic equipment, efforts have been devoted to find non-halogen flame retardant (FR) for PBT. The main envisaged alternatives have been nitrogen- and above all phosphorus-containing compounds.

\footnotetext{
* Corresponding author.

E-mail address: laurent.ferry@mines-ales.fr (L. Ferry).
}

Levchik et al. [3] studied a series of phosphazenes and derivatives to improve the fire behavior of PBT. Some of the tested FRs were shown to promote charring. However no relation was found between char promotion and fire performance, i.e. limiting oxygen index (LOI) and UL94 rating, indicating the poor efficiency of the char layer. The best results were obtained by combining phosphazene with charring polymers like poly(phenylene oxide). Two years later, Levchik et al. [4] tested a similar approach with different aryl phosphates as FRs. It was highlighted that aryl phosphates alone do not have a strong effect on flame retardancy of PBT since they do not promote charring. Moreover they tend to exude from the host polymer. Balabanovich [5] showed that a high loading (30 wt\%) of bisphenol-A bis(diphenyl phosphate) (BDP) is required to give a significant stable residue and thus an increase in LOI. Nevertheless, aryl phosphates can lead to better results when associated with cosynergist agent. For example, BDP or resorcinol bis(diphenyl phosphate) (RDP) associated with novolac phenolic resin (25 wt\% total loading) give an improvement of UL94 rating (V-0) due to the formation of an intumescent char at the surface of the sample [4]. Xiao et al. [6] showed a synergism between triphenyl phosphate (TPP) and melamine (MA). In this case, it was concluded that the FR 
system acted both in the vapor and condensed phase and enabled V-0 rating with a global additive loading of $30 \mathrm{wt} \%$. Balabanovich [7] evidenced that MA alone can improve the fire performance of PBT by promoting the formation of a solid residue consisting of condensation products of MA. However a $40 \mathrm{wt} \%$ loading is needed to obtain $26 \%$ LOI and a V-0 rating at UL94 test. Another strategy to improve UL94 rating at lower FR loading consists in combining the use of a phosphorus compound and PBT crosslinking. This was achieved by Balabanovich [8] using red phosphorus and triallyl cyanurate (TAC) as crosslinking promoter under $\gamma$ irradiation. With $12.5 \mathrm{wt} \%$ red phosphorus and $3 \mathrm{wt} \% \mathrm{TAC}$, dripping was inhibited and thus V-1 rating was obtained. In the same vein, Gao et al. [9] synthesized a novel nitrogen-phosphorus containing intumescent FR that was likely to provoke crosslinking reaction during thermal degradation and therefore to increase the char yield of PBT.

During the last decade, phosphinates have been the phosphorous chemicals that rouse the main interest as FR for PBT. First works were published by Balabanovich et al. [10] that associated 2methyl-1,2-oxaphospholan-5-one 2-oxide (OP) with ammonium polyphosphate (APP) for the flame retardancy of PBT. V-0 rating was obtained with $15 \mathrm{wt} \% \mathrm{APP}$ and $10 \mathrm{wt} \%$ OP due to a condensed phase mechanism that promotes charring and gives an intumescent effect. Thereafter the group of Schartel at BAM undertook several studies involving metal (zinc and aluminium) phosphinates as FR for PBT. It was highlighted that phosphinates act both in the condensed and gas phase [11]. In the gas phase, whatever the metal ion, the release of phosphorous species induces flame inhibition as proved by the higher $\mathrm{CO}$ production. In the condensed phase, despite a moderate increase in char yield, the presence of phosphinate induces a strong barrier effect that was assigned to the particular structure of the residue. Aluminium salt was proved to be more efficient than zinc salt [12]. In order to enhance its performance, aluminium phosphinate (AlPi) was also tested in combination with melamine derivatives $[13,14]$ or montmorillonite [15].

Despite the large literature on oxide particles and nanoparticles as component of flame retardant systems, this strategy was rarely investigated in the PBT matrix. Gallo et al. [16] studied the influence of $\mathrm{TiO}_{2}$ and $\mathrm{Al}_{2} \mathrm{O}_{3}$ nanoparticles on the fire behavior of PBT. The best results were obtained when oxides are combined with aluminum phosphinate. Phosphinate acts mainly in the gas phase while mineral nanoparticles were evidenced to have a condensed-phase action. Oxides were supposed to stabilize the polyester matrix by Lewis acid/base interactions and thereafter to promote its charring. This enabled conferring satisfying fire performance with a limited amount of additives.

Since the early works of Kashiwagi et al. [17-19], silica has been the most studied oxide for flame retardant applications. Highly porous silica was shown to slow down the decomposition kinetics of polymers due to molecular mobility restriction and trapping of decomposition products. Silica may also modify the viscoelastic properties of decomposing polymer and favor the formation of a protective layer at the sample surface. Silica was used also as synergist in intumescent FR system where it enabled reinforcing the char layer $[20,21]$. Silica was also claimed to act as smoke suppressant [22]. In order to combine the intrinsic effect of silica with the effect of a char layer, attempts have been made to prepare phosphorus-modified silica particles. In the literature, two routes may be distinguished: (i) the chemical modification of preformed silica particles, (ii) the one-step synthesis of modified silica by the so-called sol-gel process. Concerning this latter route, phosphorus-doped silicas were obtained using alkoxysilane precursors bearing a phosphorous group. This was achieved either before material processing [23] or in-situ during polymer extrusion [24-26]. With regard to the functionalization of preformed fillers, Dong et al. [27] achieved the immobilization of 9,10- dihydro-9-oxa-10-phosphaphenanthrene-10-oxide (DOPO) on silica nanoparticles. Once incorporated in polypropylene in combination with an intumescent FR system, this modified silica was proved to improve flame retardancy [28]. In a previous paper [29], we performed the grafting of phosphorous moieties onto highly porous silica particles using an alkoxysilane bearing a phosphate group. The modified silica was evidenced to increase the thermooxidative stability of polypropylene. The performance in cone calorimeter test was shown to be tightly related to the viscosity of the polymer. However the phosphorus-containing silica was unable to promote any char and thus its interest remained limited in a non-charring matrix.

In this work, a similar approach was adopted for the fireproofing of PBT, a charring polymer. Precipitated silica was surface modified by different phosphorous compounds and then incorporated in the polyester matrix. The thermal and fire behaviors were characterized. Efforts were made to elucidate the different modes of action of phosphorus-modified silica used as FR.

\section{Experimental}

\subsection{Materials and reagents}

Silica Zeosil 1165 MP (Z) was provided by Solvay. This silica is a micropearl that consists of an agglomeration of primary spherical particles of about few nanometers in diameter. The micropearl size of this silica is $250 \mu \mathrm{m}$, its BET surface area is $173 \mathrm{~m}^{2} / \mathrm{g}$ and silica Z has a porosity equal to $3.13 \mathrm{~cm}^{3} / \mathrm{g}$. Phosphoric acid (PA) and dihydrogen ammonium phosphate (DHAP) from Sigma Aldrich and diammonium phosphate (DAP) from Carlo Erba were used as flame retardant agents for the silica surface treatment. PBT (PBT Crastin ${ }^{\circledR}$ S600F40 NC010) was supplied by DuPont ${ }^{\mathrm{TM}}$. This PBT has a low viscosity and is lubricated. Its Melt Flow Index and melting point are $32.9 \mathrm{~g} / 10 \mathrm{~min}\left(250{ }^{\circ} \mathrm{C}, 2.16 \mathrm{~kg}\right)$ and $225^{\circ} \mathrm{C}$ respectively. All these products were used as received without further purification.

\subsection{Preparation of modified silicas}

Precipitated silica $Z$ was modified with PA, DHAP and DAP (respectively named ZmPA, ZmDHAP, ZmDAP). In all cases, $100 \mathrm{~g}$ of dried silica $Z$ were dispersed in $1 \mathrm{~L}$ of anhydrous ethanol with $11.1 \mathrm{~g}$ of treatment agents [30]. After $5 \mathrm{~h}$ of reaction under reflux, solvent was removed by evaporation and the resulting solid was dried at $80^{\circ} \mathrm{C}$ overnight in vacuum.

\subsection{Preparation of PBT composites}

Prior to melt processing, PBT pellets were dried at $80{ }^{\circ} \mathrm{C}$ overnight in a vacuum oven. $10 \mathrm{wt} \%$ of neat silica $\mathrm{Z}$ or modified silica were incorporated into dried PBT using a Leistritz LSM30-34 $(\mathrm{D}=34 \mathrm{~mm}, \mathrm{~L} / \mathrm{D}=34)$ co-rotating twin-screw extruder at a temperature of $240{ }^{\circ} \mathrm{C}$. The rotation speed was kept to $150 \mathrm{rpm}$ and polymer feed rate was $3 \mathrm{~kg} / \mathrm{h}$. Then composites were granulated and injection molded at $240{ }^{\circ} \mathrm{C}$ with a mold temperature equal to $60{ }^{\circ} \mathrm{C}$ using 50 Krauss-Maffei apparatus (Munich, Germany) to obtain samples with dimensions $100 \times 100 \times 4 \mathrm{~mm}^{3}$.

\subsection{Characterization}

\subsubsection{Elemental analysis}

Elemental analysis was carried out at the Institut des Sciences Analytiques (ISA, CNRS, Villeurbanne). Silicon and Phosphorus contents were determined by ICP-AES (inductively coupled plasmaatomic emission spectrometer) and carbon content by either catharometry or specific infrared detectors. 


\subsubsection{Thermogravimetric analysis (TGA)}

Thermogravimetric analysis (TGA) of silica and grafted silica were performed using a TA SDT Q600 thermal analyzer with a scan rate of $10{ }^{\circ} \mathrm{C} / \mathrm{min}$ from room temperature to $800{ }^{\circ} \mathrm{C}$ under air. Thermal analyses of composites were carried out at $10^{\circ} \mathrm{C} / \mathrm{min}$ from room temperature to $600{ }^{\circ} \mathrm{C}$ under nitrogen or air flow using a TA Q500 TGA. The tests performed under air atmosphere enable to study the thermal oxidative degradation of PBT that plays a major role in fire tests before flaming and thus may control the time to ignition. The tests performed under nitrogen atmosphere enable to study the anaerobic pyrolysis of materials which is the main degradation pathway after ignition. The second set of tests can be compared to PCFC analysis conditions.

\subsubsection{Scanning Electron Microscopy (SEM) coupled with energy} dispersive $X$-ray spectroscopy (EDX)

A Scanning Electron Microscope (FEI Quanta 200 SEM) equipped with an energy dispersive X-ray (EDX) spectrometer (Oxford INCA Energy 300) was used to study the morphology of silicas after treatment and their compositions after TGA. The fillers were placed under high vacuum before being analyzed at an accelerating voltage of $10 \mathrm{kV}$.

\subsubsection{Rheology}

The rheological behavior of composites was analyzed with a Rheometrics AR2000 mechanical spectrometer equipped with a $25 \mathrm{~mm}$ parallel plate geometry. Complex viscosity measurements were carried out with an oscillation test at $240{ }^{\circ} \mathrm{C}$ using $0.5 \%$ strain and an angular frequency ranging from $10^{-1} \mathrm{rad} / \mathrm{s}$ to $10^{2} \mathrm{rad} / \mathrm{s}$.

Samples were prepared by compression molding at $240^{\circ} \mathrm{C}$ in the form of $25 \mathrm{~mm}$ in diameter and $1 \mathrm{~mm}$ thick discs.

\subsubsection{Fire behaviour}

The combustion properties of the composites were estimated using a Pyrolysis Combustion Flow Calorimeter (PCFC) analysis. Tests were carried out in duplicate according to the anaerobic pyrolysis method of the ASTM D7309 (method A) using a Fire Testing Technology FTT apparatus. 2-4 mg of sample was pyrolyzed under nitrogen flow up to $750{ }^{\circ} \mathrm{C}$ at a heating rate of $1{ }^{\circ} \mathrm{C} / \mathrm{s}$. Gases are extracted and sent to a combustion chamber in presence of $\mathrm{O}_{2} / \mathrm{N}_{2}$ (20/80) with a controlled constant flow of $100 \mathrm{~cm}^{3} / \mathrm{min}$. The combustion temperature was fixed at $900{ }^{\circ} \mathrm{C}$ in order to reach a complete combustion. The measurement of oxygen depletion during the test leads to the Heat Release Rate (HRR) according to the Huggett's relation [31] (1 kg of consumed oxygen corresponds to $13.1 \mathrm{MJ}$ of released energy).

The flammability of the samples was also determined by a Fire Testing Technology FTT Cone Calorimeter. Tests were performed in accordance with the International Standard ISO 5660-1, using aluminium foil in order to prevent dripping of molten material. The specimens $(100 \times 100 \mathrm{~mm}$ section, $4 \mathrm{~mm}$ thickness) were horizontally exposed to an irradiance of $50 \mathrm{~kW} / \mathrm{m}^{2}$. Each formulation was tested in duplicate. Peak of heat release rate (pHRR), Total Heat Release (THR), Time To Ignition (TTI), Residual mass and Effective Heat of Combustion (EHC) are reported. Moreover, to evaluate the fire growth of samples, two parameters were calculated: FIGRA (fire growth rate index), as the ratio of pHRR and time to pHRR, and pHRR/TTI [32,33].

The uncertainties in measurements for both apparatus are about $5 \%$ and $15 \%$ respectively.

To get an insight on ignition, the upper surface temperature of composites was also measured by an infrared (IR) camera (Optristemperature range $125-900^{\circ} \mathrm{C}$ ) during a cone calorimeter test. The specimens were exposed to an irradiance of $15 \mathrm{~kW} / \mathrm{m}^{2}$ in order to highlight phenomena that could take place before ignition.
Specimens were placed $60 \mathrm{~mm}$ under the conic heater. The IR camera was placed in an inclined position above the specimen. The apparatus is presented in Fig. 1.

\section{Results and discussion}

\subsection{Thermal behaviour of modified silicas}

The thermogravimetric analysis (TGA) results, shown in Fig. 2a, evidence the surface modification of silica $Z$. Without prior treatment, unmodified silica exhibits a total mass loss of approximately $8 \mathrm{wt} \%$. The main mass loss (ca. $6 \mathrm{wt} \%$ ) occurs between room temperature and $120^{\circ} \mathrm{C}$ and can be attributed to the desorption of physically bonded water [34]. A further mass loss is observed at higher temperature that can be assigned to silica dehydroxilation [35]. The TGA curves of modified silicas differ somewhat from that of pure silica. ZmDHAP, ZmDAP show a first mass loss at low temperature (up to $120^{\circ} \mathrm{C}$ ) that is related to the loss of water and solvent residues loosely bonded to the silica surface. However it should be noted that this mass loss represents only $1.6 \mathrm{wt} \%$ indicating that water sorption was significantly reduced by the surface treatment. Above $200{ }^{\circ} \mathrm{C}$ these two modified silicas exhibit a continuous mass loss up to $800^{\circ} \mathrm{C}$ where the final mass loss is respectively $11 \mathrm{wt} \%$ and $9 \mathrm{wt} \%$ for $\mathrm{ZmDHAP}$ and ZmDAP. In the case of ZmPA the mass loss is almost continuous from $60{ }^{\circ} \mathrm{C}$ to $800{ }^{\circ} \mathrm{C}$ with a final mass loss of $7.5 \mathrm{wt} \%$. It is obvious that mass losses observed on modified silicas between $150{ }^{\circ} \mathrm{C}$ and $800^{\circ} \mathrm{C}$ are related to the decomposition of the surface treatment. Nevertheless the difference between the TGA curves of pure reactants (Fig. 2b) and the thermal behavior of $\mathrm{ZmPA}$, ZmDHAP and ZmDAP (Fig. 2a.) suggests that the decomposition pathway of PA, DHAP and DAP is changed when grafted onto silica. Hence it is difficult to determine by this method the initial grafting rate as well as the amount of surface treatment remaining in the high temperature residue.

In order to get more information about these two parameters, elemental analysis (EA) was performed on the initial modified silicas while EDX analysis was carried out on their TGA residues. The rate of phosphorus contained in initial $\mathrm{ZmPA}, \mathrm{ZmDHAP}$ and $\mathrm{ZmDAP}$ is low and equal to respectively $3.2 \mathrm{wt} \%, 4.4 \mathrm{wt} \%$ and $2.5 \mathrm{wt} \%$

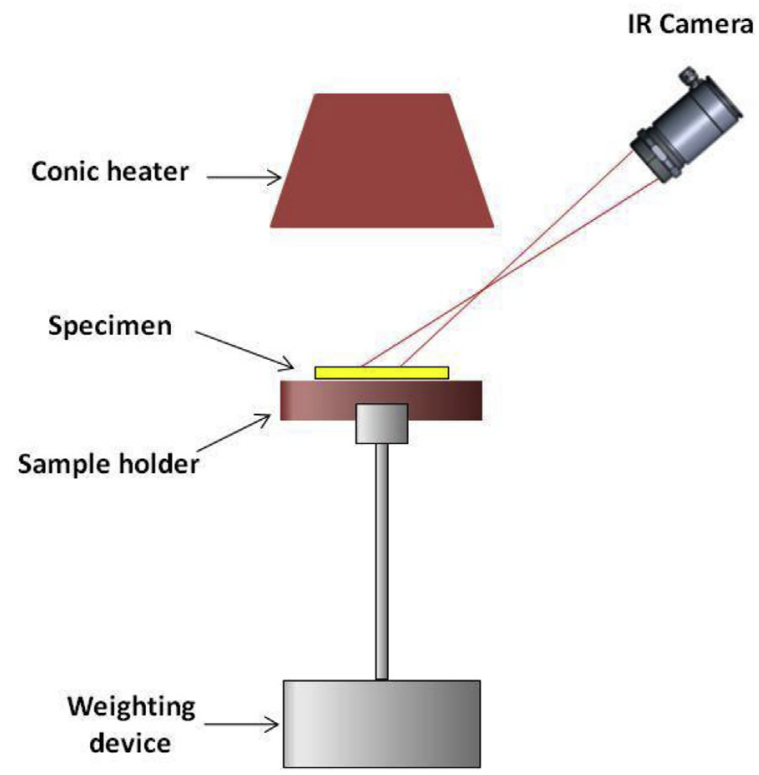

Fig. 1. Scheme of cone calorimeter test equipped with IR camera. 

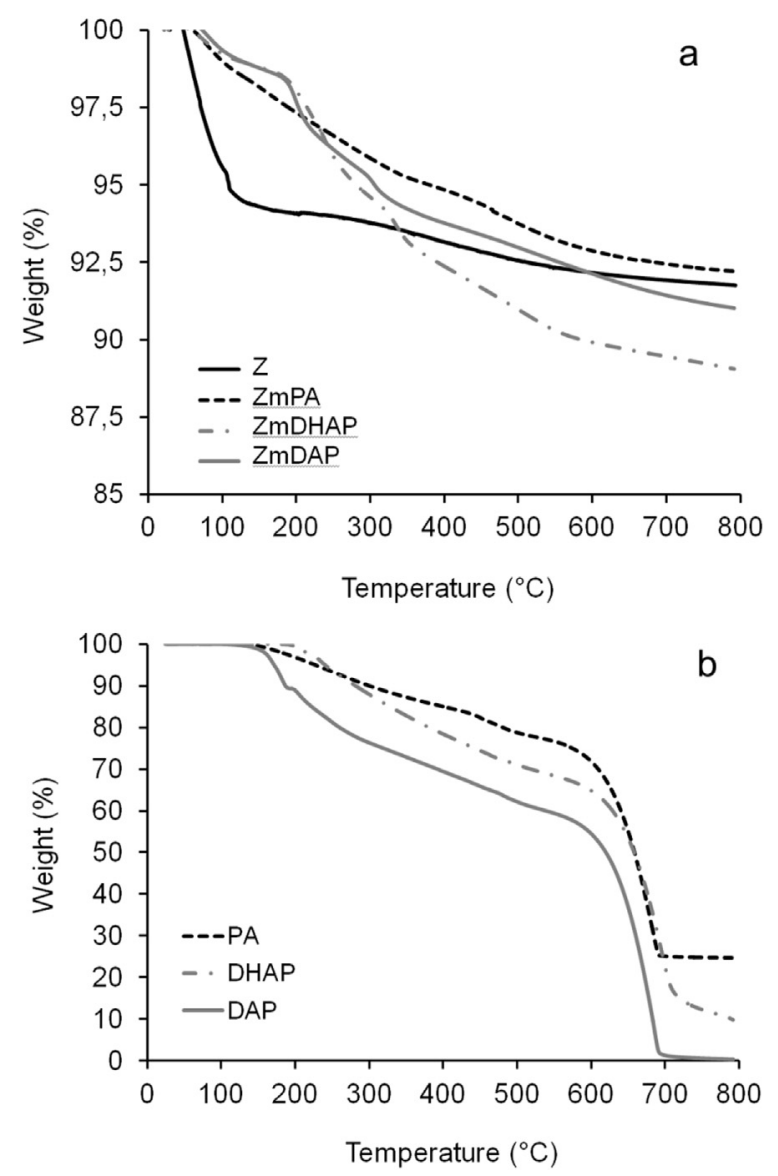

Fig. 2. TGA curves for (a) silica $\mathrm{Z}$ and modified silica $\mathrm{ZmPA}, \mathrm{ZmDHAP}$ and $\mathrm{ZmDAP}$ and (b) phosphorous compounds under air.

(Table 1). Thanks to these rates, the quantity of phosphorous flame retardant agent grafted onto silica surface was estimated at $10.1 \mathrm{wt}$ $\%, 16.3 \mathrm{wt} \%$ and $10.6 \mathrm{wt} \%$ respectively. The fraction of initial phosphorus content remaining in the residue $f_{\text {Pcond }}$ is calculated from Eq. (1).

$f_{\text {Pcond }}=\frac{X_{\text {residue }} \times X_{\text {Pcond }}}{X_{\text {Pini }}}$

where $\mathrm{X}_{\text {residue }}$ is the residue yield measured by TGA, $\mathrm{X}_{\text {Pcond }}$ is the phosphorus content in the residue determined by EDX and $\mathrm{X}_{\mathrm{Pini}}$ is the phosphorus content in the initial material determined by EA. According to $\mathrm{f}_{\text {Pcond }}$ calculations, the major part of phosphorus remains in the condensed phase after thermal degradation of modified silica. Indeed, the fractions of phosphorus remaining in $\mathrm{ZmPA}$, $\mathrm{ZmDHAP}$ and $\mathrm{ZmDAP}$ residues are close to 1 (respectively $0.9,0.9$ and 0.7 ), which suggests that phosphorus could contribute to the char formation during PBT composite combustion.
Table 2

Results of elemental analysis for PBT composites.

\begin{tabular}{llllll}
\hline & $\mathrm{C}(w \mathrm{w} \%)$ & $\mathrm{Si}(w \mathrm{t} \%)$ & $\mathrm{P}(w t \%)$ & $\mathrm{P} / \mathrm{Si}$ & Rate of filler $^{\mathrm{a}}$ (wt\%) \\
\hline PBT-Z-10\% & 59.8 & 3.19 & 0 & 0 & 6.8 \\
PBT-ZmPA-10\% & 59.5 & 3.18 & 0.18 & 0.057 & 7.6 \\
PBT-ZmDHPA-10\% & 60.0 & 2.71 & 0.22 & 0.081 & 6.9 \\
PBT-ZmDAP-10\% & 59.3 & 3.27 & 0.20 & 0.061 & 7.8 \\
\hline
\end{tabular}

a Calculated from Si values.

\subsection{Thermal and fire properties of PBT/silica composites}

\subsubsection{Composition of the composite materials}

The mass fractions of carbon, silicon and phosphorus elements in the composites were determined by elemental analysis and are presented in Table 2 .

The elemental analysis shows a phosphorus content around $0.2 \mathrm{wt} \%$ whatever the modified silica. A comparison between Tables 1 and 2 indicates that $\mathrm{P} / \mathrm{Si}$ ratio is almost constant in the case of ZmDAP and slightly decreases for the two other modified silicas, which shows a slight loss of phosphorus during composites preparation. From these results, the actual rates of fillers were calculated according to Si content considering that grafted phosphorous agents (rates presented in Table 1) remain totally in the composite during the extrusion process. The rate of filler was found to be lower than the expected value of $10 \mathrm{wt} \%$.

\subsubsection{Thermal behavior}

The PBT thermal degradation under inert or oxidative atmosphere has been widely reported in the literature [9,11,16,36-40]. As presented in those studies, the thermograms depicted in Fig. 3 show a one-step degradation for PBT and PBT composites under inert atmosphere. The degradation of PBT occurs between $300{ }^{\circ} \mathrm{C}$ and $450{ }^{\circ} \mathrm{C}$ for all samples. As presented in Table 3 the onset decomposition temperature corresponding to a $5 \%$ weight loss is $369{ }^{\circ} \mathrm{C}$ for PBT and PBT-Z-10\% whereas this temperature is shifted to lower temperature for PBT containing modified silica (down to $348{ }^{\circ} \mathrm{C}$ for PBT-ZmDHAP-10\%) which could be due to the early decomposition of phosphorous compounds [30]. However it should be noted that the incorporation of pure silica or modified silica does not lead to a significant change of the thermal stability of the polyester under He with a peak of mass loss rate (pMLR) temperature of about $396 \pm 4{ }^{\circ} \mathrm{C}$. Under thermo-oxidative conditions, PBT shows the same temperature of PMLR than under inert conditions and the incorporation of pure or modified silica has no effect on this temperature. Nazare et al. [38] and Yang et al. [41] have already reported that clays do not change the thermal stability of PBT. The authors explained that clays may have antagonist effect on PBT degradation. On one hand, silicate can act as barrier to decomposition products which could increase the thermal stability of PBT. On the other hand, clays can act as catalytic agent for the polymer decomposition, which finally may explain that there is no modification of the PBT thermal stability. In our case, we simply suggest that silica acts as an inert additive.

Table 1

Modified silica ZmPA, ZmDHAP and ZmDAP compositions.

\begin{tabular}{|c|c|c|c|c|c|c|c|}
\hline & \multirow[b]{2}{*}{$\mathrm{X}_{\text {residue }}{ }^{\mathrm{a}}(\mathrm{wt} \%)$} & \multicolumn{4}{|c|}{ EA results on initial silicas } & \multirow{2}{*}{$\frac{\text { EDX results on residues from TGA }}{\mathrm{X}_{\text {Pcond }}(\mathrm{wt} \%)}$} & \multirow[t]{2}{*}{$\mathrm{f}_{\text {Pcond }}$} \\
\hline & & $\mathrm{Si}(\mathrm{wt} \%)$ & $\mathrm{X}_{\text {Pini }}(\mathrm{wt} \%)$ & $\mathrm{P} / \mathrm{Si}$ & Phosphorous agent $^{\mathrm{b}}$ (wt\%) & & \\
\hline ZmPA & 92.1 & 33.4 & 3.2 & 0.095 & 10.1 & 3.1 & 0.9 \\
\hline ZmDHAP & 88.9 & 34.3 & 4.4 & 0.130 & 16.3 & 4.3 & 0.9 \\
\hline ZmDAP & 90.7 & 36.0 & 2.5 & 0.069 & 10.6 & 2.0 & 0.7 \\
\hline
\end{tabular}

a Rate of residues from TGA.

b Calculated from $\mathrm{X}_{\text {Pini. }}$ 

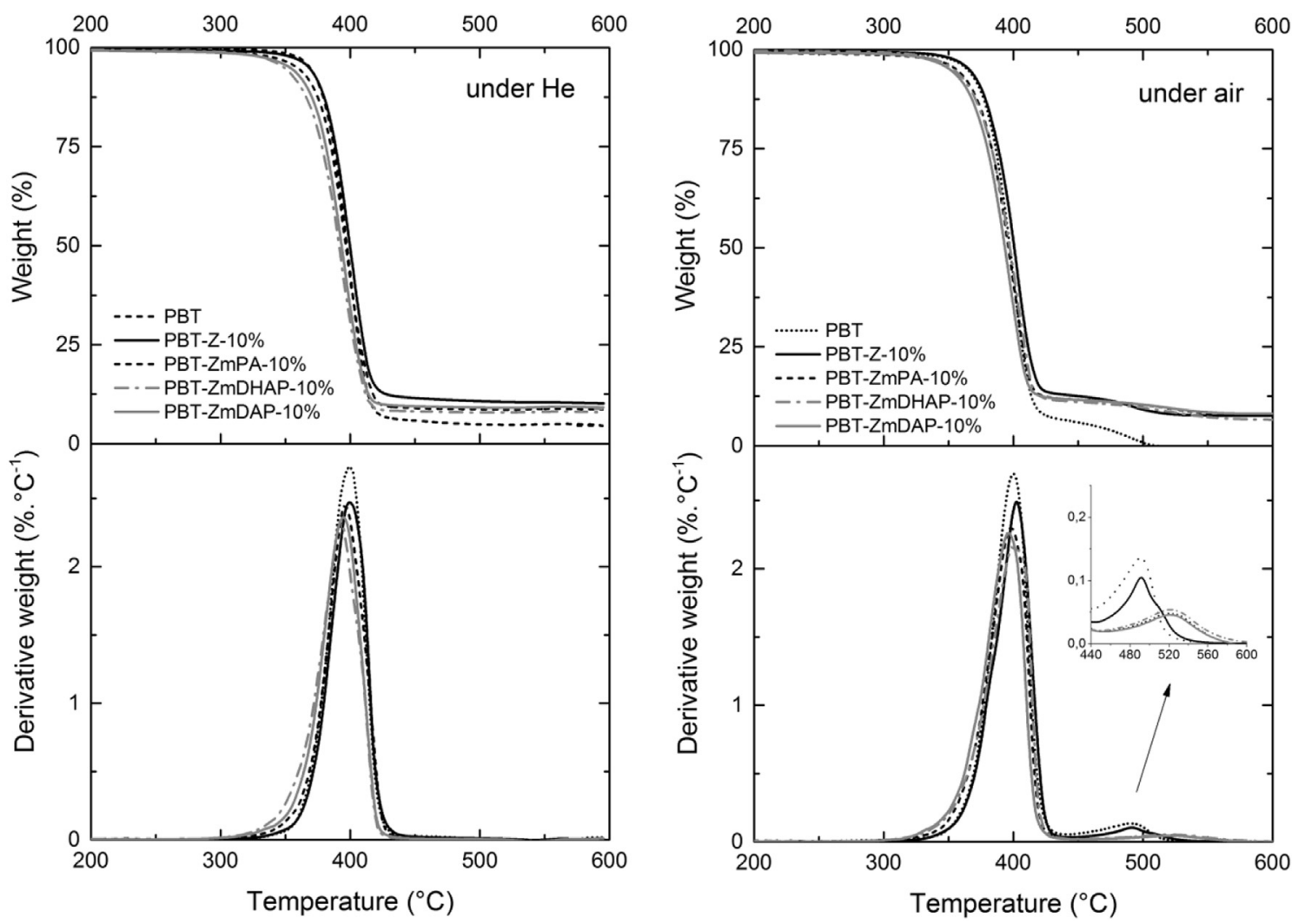

Fig. 3. TGA curves for PBT and PBT composites containing silica $\mathrm{Z}$ and modified silica ZmPA, ZmDHAP and ZmDAP under He and air.

Table 3

TGA results for PBT composites.

\begin{tabular}{lllll}
\hline & $\mathrm{T}_{5 \%}\left({ }^{\circ} \mathrm{C}\right)$ & $\mathrm{T}_{\mathrm{deg}}\left({ }^{\circ} \mathrm{C}\right)$ & $\begin{array}{l}\text { Filler content }^{\mathrm{a}} \\
(\text { wt\% })\end{array}$ & $\begin{array}{l}\text { Char yield }^{\mathrm{b}} \\
(\text { wt\% })\end{array}$ \\
\hline PBT & 369 & 399 & 0 & 3.5 \\
PBT-Z-10\% & 369 & 400 & 7.6 & 2.1 \\
PBT-ZmPA-10\% & 359 & 396 & 7.6 & 2.0 \\
PBT-ZmDHAP-10\% & 348 & 392 & 6.6 & 1.2 \\
PBT-ZmDAP-10\% & 353 & 395 & 7.9 & 1.1 \\
\hline
\end{tabular}

a Residue content at $600{ }^{\circ} \mathrm{C}$ under air.

b Calculated as the difference of the residue content under air and the residue content under $\mathrm{He}$ at $600{ }^{\circ} \mathrm{C}$.

The major difference between TGA results under inert or oxidative atmosphere is that under air, PBT presents a two-step degradation where the second degradation at about $490{ }^{\circ} \mathrm{C}$ corresponds to the decomposition of the char residue formed during the first step (PBT degradation) [40]. It must be noticed that whereas PBT-Z-10\% shows the same temperature of char decomposition as neat PBT, the introduction of phosphorous modified silica improves the stability of the char by $15^{\circ} \mathrm{C}$.

Concerning the yield of residue, under oxidative atmosphere, PBT decomposes completely at about $550{ }^{\circ} \mathrm{C}$ (Table 3). Under air, the rate of residue corresponds to the actual rate of fillers introduced during melt processing. This rate of fillers is respectively $7.6 \mathrm{wt} \%, 7.6 \% \mathrm{wt}, 6.6 \mathrm{wt} \%$ and $7.9 \mathrm{wt} \%$ for PBT-Z-10\%, PBT-ZmPA- $10 \%$, PBT-ZmDHAP-10\% and PBT-ZmDAP-10\%. These values are very close to those determined by elemental analysis (see Table 2). Under inert atmosphere, the degradation of PBT leads to the formation of a $3.5 \mathrm{wt} \%$ residue as reported in Table 3. This difference in residue yield under air and inert atmosphere corresponds to the rate of stable char. As shown in Table 3, the addition of silica seems to decrease the rate of char formed during PBT thermal degradation. The effect is even more pronounced for modified silicas since the residue yield drops down to $1.1 \mathrm{wt} \%$. for PBT-ZmDAP- $10 \%$. Surprisingly it means that phosphorus inhibits polymer charring.

\subsubsection{Fire behavior}

Thermogravimetric analysis can be completed by the study of the fire behavior of PBT composites thanks to pyrolysis combustion flow calorimeter (PCFC) for mg-sizes samples and cone calorimeter for bigger samples (i.e. about 50 g). The Heat Release Rate (HRR) curves for the composites measured using PCFC are illustrated in Fig. 4. These curves can be compared to DTG curves (Fig. 3) obtained by TGA under He.

The temperature, for which peak of Heat Release Rate (pHRR) is observed, is about $411{ }^{\circ} \mathrm{C}$, and is the same for every sample considering the uncertainties in measurements, which is in accordance with the TGA results (Fig. 3). It should be noted that a decrease of pHRR is observed for any silica introduced into the PBT. Indeed, the pHRR of neat PBT is $518 \mathrm{~W} / \mathrm{g}$ whereas for all composites pHRR is almost the same and equals to $450 \mathrm{~W} / \mathrm{g}$. This corresponds to a $13 \%$ decrease of the PBT pHRR, which is slightly higher than actual introduced amount of fillers. The Total Heat Release (THR) during the combustion is about the same for every composite and equals to about $19.6 \mathrm{~kJ} / \mathrm{g}$ (and $20.2 \mathrm{~kJ} / \mathrm{g}$ for pure PBT). The change of fire properties evaluated in PCFC is caused by the substitution of the organic polymer matrix by inert fillers (dilution of fuels in condensed phase) without creating additional char, which is in accordance with TGA results (Table 2). Silica, including modified silica, can be considered as inert filler at this microscale.

The fire behavior of PBT samples evaluated using cone calorimeter is illustrated by results presented Table 4 and Fig. 5 .

The HRR curves (Fig. 5) reveal a modification of combustion 


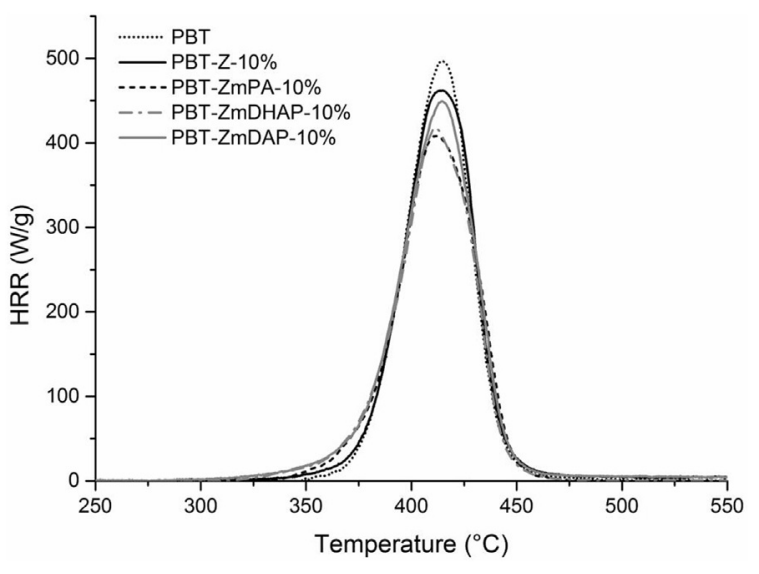

Fig. 4. $P C F C$ curves $P B T$ and $P B T$ composites containing silica $Z$ and modified silica $\mathrm{ZmPA}, \mathrm{ZmDHAP}$ and ZmDAP.

behavior when fillers are added in PBT compared to neat polyester. Indeed, neat PBT shows a sharp HRR curve between 60s and 250s with a pHRR of $1250 \mathrm{~kW} / \mathrm{m}^{2}$ (Table 4). The dispersion of untreated silica $\mathrm{Z}$ leads to a slight change of the curve shape with a decrease of TTI of about 20s and a 27\% decrease of the pHRR compared to neat PBT. When silica is modified by phosphorous FR agents, the curve presents a significant change of shape which is characteristic of thermally thick charring or residue forming materials as described by Schartel et al. [32]. The TTI of composites containing ZmPA, ZmDHAP and ZmDAP is higher than PBT-Z-10\% but 10s lower than PBT. The pHRR is reduced by at least $54 \%$ when modified fillers are introduced in the polymer matrix.

The evolution of TTI is not consistent with TGA results under oxidative atmosphere which suggest that PBT-Z-10\% should have the same TTI than PBT. Moreover, the slight decrease of the thermal stability of composites containing modified silica should lead to a reduction of TTI compared to PBT and PBT-Z-10\%. Nazare et al. [38] have already observed a decrease of TTI when $5 \mathrm{wt} \%$ of sepiolite amine (SP) or $5 \mathrm{wt} \%$ of montmorillonite Cloisite 30B (CL 30B) were added into PBT. Indeed under an irradiance of $50 \mathrm{~kW} / \mathrm{m}^{2}$, the PBT used by the authors presents a TTI of $64 \mathrm{~s}$, whereas those of PBT + SP and PBT + CL $30 B$ are equal to $44 \mathrm{~s}$ and $51 \mathrm{~s}$ respectively. Nazare et al. have done the hypothesis that the increase of viscosity of their PBT composites compared to neat PBT could play a role in this modification of TTI by decreasing the heat transfer by flowing of the molten polymer. This phenomenon could lead to an accumulation of heat at the upper surface of the material and therefore to an early ignition. In order to explain results presented in Table 4 regarding TTI, cone calorimeter tests were performed under an irradiance of $15 \mathrm{~kW} / \mathrm{m}^{2}$ and using an IR camera as explained above (Fig. 1). This apparatus enables to measure the upper surface temperature of samples during their combustion which can allow us to evaluate phenomena inducing ignition, based on the hypothesis that these phenomena are the same at $15 \mathrm{~kW} / \mathrm{m}^{2}$ and $50 \mathrm{~kW} / \mathrm{m}^{2}$. The results of this measurement are given in Fig. 6 for PBT and PBT-ZmPA-10\%.

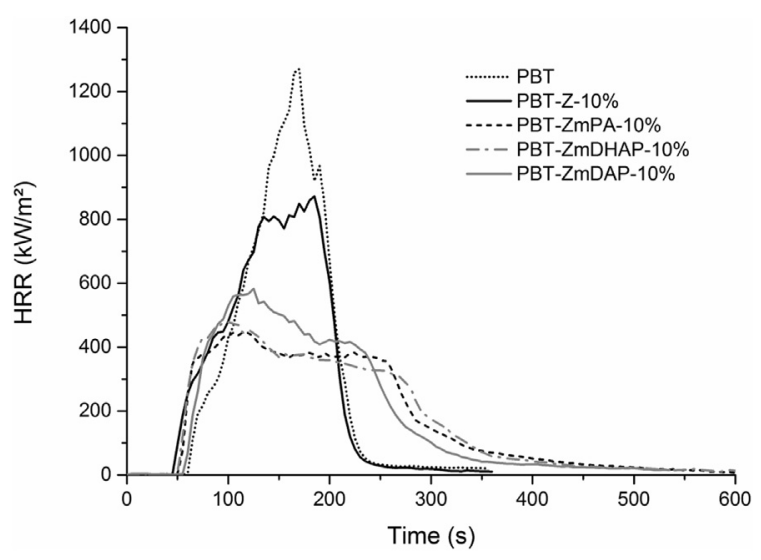

Fig. 5. Cone calorimeter curves $\mathrm{PBT}$ and $\mathrm{PBT}$ composites containing silica $\mathrm{Z}$ and modified silica ZmPA, ZmDHAP and ZmDAP.

It should be noticed that up to the PBT melting $\left(210^{\circ} \mathrm{C}\right)$, the heating rate is the same for both samples. Above $210^{\circ} \mathrm{C}$, two distinct behaviors can be described: the heating of PBT containing fillers is faster than neat PBT for which TTI at $50 \mathrm{~kW} / \mathrm{m}^{2}$ is higher than the composites one. Moreover, PBT-ZmPA-10\% ignites after 250s whereas PBT does not present any ignition even after 300s. The observed ignition temperature is consistent with that measured by Lyon et al. i.e. $382{ }^{\circ} \mathrm{C}$ [42].The heating acceleration is correlated with the bubbling appearance after melting of PBT when fillers are incorporated into the polyester. Such a phenomenon has already been observed by Oztekin et al. [43] during their studies on the fire behavior of poly(aryl ether ether ketone) (PEEK). The authors have compared the behavior of wet and dry PEEK and have shown that after melting bubbles appear when water is trapped in the polymer. These bubbles lead to an increase of heat adsorption at the upper surface thus inducing modifications of thermal and optical

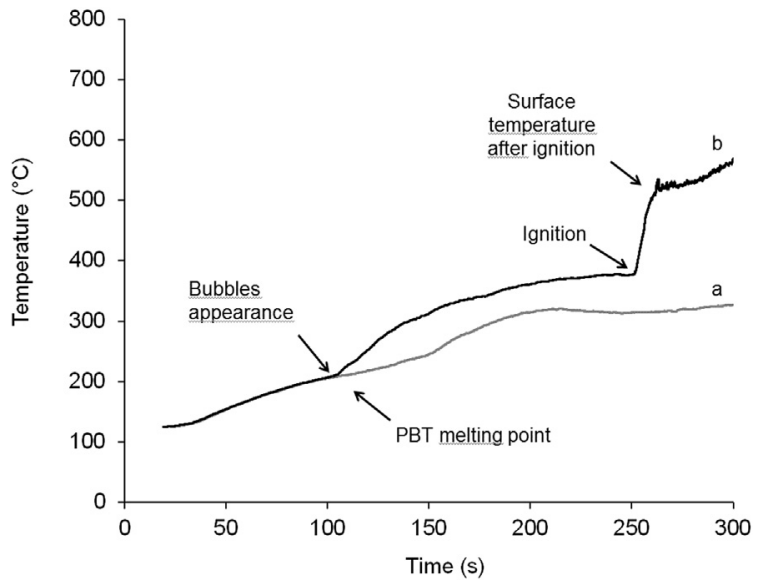

Fig. 6. Temperature of the upper surface for (a) PBT and (b) PBT-ZmPA-10\%.

Table 4

Cone calorimeter results for PBT composites.

\begin{tabular}{|c|c|c|c|c|c|c|}
\hline & $\operatorname{TTI}(\mathrm{s})$ & $\mathrm{pHRR}\left(\mathrm{kW} / \mathrm{m}^{2}\right)$ & $\mathrm{THR}\left(\mathrm{kW} / \mathrm{m}^{2}\right)$ & $\mathrm{EHC}(\mathrm{kJ} / \mathrm{g})$ & FIGRA $\left(\mathrm{kW} / \mathrm{m}^{2} . \mathrm{s}\right)$ & $\begin{array}{l}\text { pHRR/TTI } \\
\left(\mathrm{kW} / \mathrm{m}^{2} . \mathrm{s}\right)\end{array}$ \\
\hline PBT & 60 & 1250 & 108 & 20.2 & 7.1 & 20.8 \\
\hline PBT-Z-10\% & 42 & 911 & 99 & 19.6 & 5.1 & 21.7 \\
\hline PBT-ZmPA-10\% & 48 & 453 & 102 & 19.5 & 4.3 & 9.4 \\
\hline PBT-ZmDHAP-10\% & 47 & 495 & 104 & 19.8 & 5.0 & 10.5 \\
\hline PBT-ZmDAP-10\% & 51 & 573 & 102 & 19.9 & 5.1 & 11.2 \\
\hline
\end{tabular}


properties. Such an increase leads to an early ignition, with a TTI of 207s for dry PEEK against 110 s for wet PEEK at $50 \mathrm{~kW} / \mathrm{m}^{2}$. The role of bubbling was also highlighted by Fina et al. in polypropylene/ nanoclay composites [44]. The same phenomenon was observed for the other PBT composites (not shown here): bubbles are observed for composites having the shortest TTI at 15 and $50 \mathrm{~kW} / \mathrm{m}^{2}$.

In order to rank samples in terms of flame spread, pHRR/TTI and FIGRA were calculated and results are given in Table 4. The lower are those parameters, the better are the fire properties. In terms of FIGRA, the introduction of any fillers leads to a decrease of at least $28 \%$ of the fire growth index, and down to $40 \%$ for PBT-Zm-PA- $10 \%$. This reduction is mainly related to the significant decrease of pHRR in the case of modified silica containing PBT.

Regarding the pHRR/TTI values, the decrease is almost the same for composites containing the three modified silicas ZmPA, ZmDHAP and ZmDAP (a 50\% decrease approximately) while the introduction of pure silica does not lead to a reduction of this fire growth parameter compared to neat PBT. Those results show the interest of modifying silica by phosphorous fire retardant agent in order to improve the fire behavior of PBT.

The reduction of pHRR for all composites is more marked than in PCFC since cone calorimeter test takes into account additional physical effects like barrier effect. To evaluate this barrier effect in PBT, results obtained using PCFC and cone calorimeter were compared [45-47]. The method consists in plotting the two parameters $\mathrm{R} 1$ versus $\mathrm{R} 2$, which are defined as the ratio between pHRR of the composite and of the pure polymer in PCFC and in cone calorimeter respectively (Eq. (2) ad Eq. (3)). The more the plotted points are above the dotted line $\mathrm{R} 1=\mathrm{R} 2$ (i.e. $\mathrm{R} 1 \gg \mathrm{R} 2$ ), the higher the barrier effect is.

$R_{1}=\frac{p H R R(\text { composite }) \text { in PCFC }}{p H R R(P B T) \text { in PCFC }}$

$R_{2}=\frac{p H R R(\text { composite }) \text { in cone calorimeter }}{p H R R(P B T) \text { in cone calorimeter }}$

As presented in Fig. 7, for PBT composites, all points are shifted from the line $\mathrm{R} 1=\mathrm{R} 2$, which means that the improvement of fire retardancy of PBT containing silica and more particularly modified silica, is due to physical barrier effect.

The Effective Heat of Combustion (EHC) values (Table 4) confirm that the decrease of pHRR is only due to physical effects in the condensed phase, since EHC is constant and equal to about $20 \mathrm{~kJ} / \mathrm{g}$ for every sample (which is very close to the energy of complete combustion for pure PBT). The very small amount of phosphorus in PBT/modified silica composites does not lead to any flame inhibition effect in gas phase. The elemental analyses of cone residue are in accordance with these results. Indeed, the fraction of phosphorus content in the cone calorimeter residue at the end of the test $\left(\mathrm{f}_{\text {cond }}\right)$ calculated according to Eq. (1), is close to 1 whatever the PBT composite containing modified silica. $\mathrm{f}_{\mathrm{Pcond}}$ suffers from approximation due to the accuracy of $\mathrm{X}_{\text {residue }}$ and $\mathrm{X}_{\text {Pcond }}$ measurement and should be considered rather as an indicator. That is why a value greater than one was obtained for PBT-ZmDAP-10\%. Nevertheless high values of $\mathrm{f}_{\text {Pcond }}$ indicate that nearly the totality of phosphorus remains in the condensed phase during the combustion of materials. Therefore the phosphorous agent cannot act in the gas phase as flame inhibitor.

Regarding the residue content after burning, it must be noticed that this one is $10.1 \mathrm{wt} \%$ for PBT-Z-10\% and $8.5 \mathrm{wt} \%, 7.8 \mathrm{wt} \%$ and $9.6 \mathrm{wt} \%$ for PBT composites containing ZmPA, ZmDHAP and ZmDAP respectively. The residual char obtained after combustion of neat PBT is equal to $2.4 \mathrm{wt} \%$. These results are consistent with filler contents and char yields as determined from TGA experiments (see

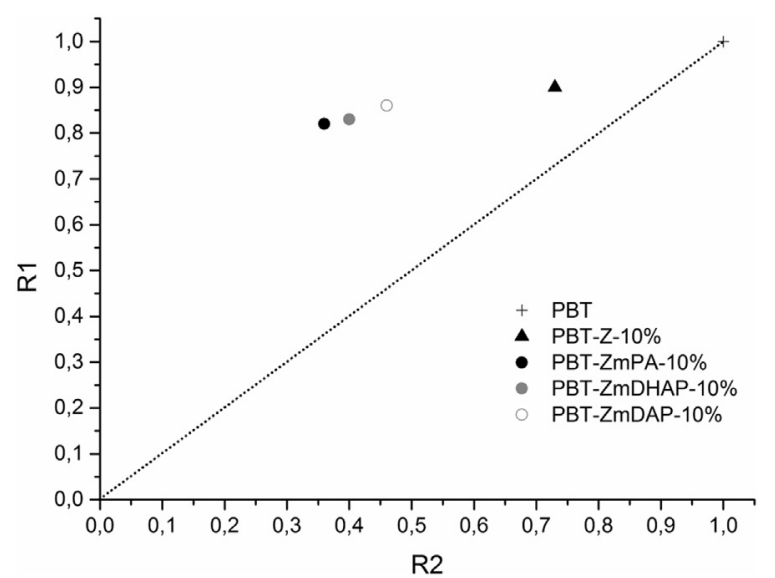

Fig. 7. $\mathrm{R} 1$ vs $\mathrm{R} 2$ pots for $\mathrm{PBT}$ and $\mathrm{PBT}$ composites containing silica $\mathrm{Z}$ and modified silica ZmPA, ZmDHAP and ZmDAP.

Table 3) and suggest that the char yield slightly decreases with the introduction of modified silica. This is confirmed by the fraction of carbon remaining in the residue after combustion and calculated according to Eq. (4). Not only the fraction of carbon in condensed phase is very low (less than 0.01 ), but also fcond $_{\text {decreases by } 40 \%}$ when modified silicas are introduced into PBT. The residues of composites are mainly constituted of silica.

$f_{\text {Ccond }}=\frac{X_{\text {residue }} \times X_{\text {Ccond }}}{X_{\text {Cini }}}$

Moreover, the THR values (Table 4) of the samples, highlight a very limited decrease of at least $3.7 \%$ for PBT-ZmDHAP-10\% and of maximum $8 \%$ for PBT-Z-10\%, compared to the THR of neat PBT, which is equal to $108 \mathrm{~kW} / \mathrm{m}^{2}$ (or $19.7 \mathrm{~kJ} / \mathrm{g}$ ). These results suggest that the phosphorus remaining in condensed phase does not promote charring of the PBT, which is in accordance with the amount of residue (Xresidue) at the end of cone calorimeter test and carbon ( $\left.\mathrm{X}_{\text {Ccond }}\right)$ content in this residue presented in Table 5.

As shown from the pictures in Fig. 8, the upper surface of samples is grey, which indicates the very slight amount of char after PBT burning. It should be noted that the cone calorimeter residues of PBT/modified silica composites are expanded and cover the whole surface contrary to PBT-Z-10\%. Indeed, the residue of PBT-Z$10 \%$ is about $1 \mathrm{~mm}$ thick whereas those of PBT containing silica ZmPA, ZmDHAP and ZmDAP are $5 \mathrm{~mm}$ thick. Such an expansion could play a major role in the efficiency of the barrier effect, by forming a protective layer to the mass and thermal transfer. This is a phenomenon of intumescence $[11,48,49]$ which leads to a decrease of pHRR. The SEM micrographs also reveal that the residues of PBT/ modified silica composites are more porous that those of PBT and PBT-Z-10\% which are more cohesive, which is consistent with the difference of expansion.

\subsection{Influence of viscosity on fire retardancy}

As discussed above, the improvement of PBT fire behavior by addition of phosphorus modified silica may be attributed to physical mechanism in the condensed phase, as for instance barrier effect. The specific aspect of the fire behavior of PBT/modified silica composites is the intumescence of samples contrary to PBT and PBT-Z-10\%. The amount of ammonium in PBT/modified silica does not have an effect on the expansion of the cone calorimeter residue since PBT-ZmPA-10\% presents the same behavior as PBT$\mathrm{ZmDAP}-10 \%$, without any presence of ammonium in ZmPA. Clerc 
Table 5

Cone calorimeter results for PBT composites.

\begin{tabular}{|c|c|c|c|c|c|c|c|c|}
\hline & $\mathrm{X}_{\text {residue }}^{\mathrm{a}}(\mathrm{wt} \%)$ & $\mathrm{X}_{\text {Ccond }}(\mathrm{wt} \%)$ & $\mathrm{X}_{\text {Sicond }}(\mathrm{wt} \%)$ & $\mathrm{X}_{\text {Pcond }}(\mathrm{wt} \%)$ & $\mathrm{X}_{\mathrm{Cini}} \mathrm{b}^{\mathrm{b}}(\mathrm{wt} \%)$ & $\mathrm{X}_{\text {Pini }}{ }^{\mathrm{b}}(\mathrm{wt} \%)$ & $\mathrm{f}_{\text {Ccond }}$ & $\mathrm{f}_{\text {Pcond }}$ \\
\hline PBT & 2.4 & 19.6 & 0 & 0 & 65.5 & 0 & 0.007 & - \\
\hline PBT-Z-10\% & 10.1 & 5.8 & 39.2 & 0 & 59.8 & 0 & 0.010 & - \\
\hline PBT-ZmPA-10\% & 8.5 & 3.4 & 36.1 & 2.06 & 59.5 & 0.18 & 0.005 & 1.00 \\
\hline PBT-ZmDHAP-10\% & 7.8 & 3.0 & 37.0 & 2.82 & 60.0 & 0.22 & 0.004 & 1.00 \\
\hline PBT-ZmDAP-10\% & 9.6 & 2.4 & 37.5 & 2.44 & 59.3 & 0.20 & 0.004 & 1.15 \\
\hline
\end{tabular}

${ }^{\text {a }}$ Rate of residues from cone calorimeter at the end of the test.

b From Table 2.

et al. [49] have shown in their studies that viscosity could have an effect on the char expansion. They showed that materials (in their studies EVA containing lamellar particles) presenting an average viscosity (neither too low, nor too high), present the highest cone calorimeter residue thickness after burning. Actually, such a viscosity enables to trap bubbles and thus creates a swollen structure. If the viscosity is too high, bubbles will not spread and grow inside the material. Therefore the final thickness of the cone calorimeter residue decreases. Furthermore, Kashiwaghi et al. [18,19,50,51] and Batistella et al. [47] have already reported that the viscosity of materials has an impact on fire behavior, which was also shown in our previous studies concerning the polypropylene fire behavior [29].

Kashiwaghi et al. have observed the impact of viscosity on fire behavior of polymethylmethacrylate (PMMA) [19,50,51] and with polypropylene (PP) in their studies in collaboration with Gilman $[17,18]$, when silica are introduced into both polymers. The authors have suggested that an increase of the viscosity may have an effect on the accumulation rate of silica at the upper surface of the sample during its combustion. Regarding PP, Kashiwagi et al. have compared the impact of four different silicas (fused silica, fumed hydrophilic, fumed hydrophobic and silica gel) at a loading rate of 10 wt\% [18]. They have highlighted that the highest viscosity is obtained for $\mathrm{PP} /$ silica gel composite, and leads to the highest decrease of mass loss rate during combustion, and therefore leads to the best fire performance. On the opposite PP/fused silica presents the worst fire behavior since its low viscosity leads to a sinking of the filler through the polymer layer. Therefore fused silica does not accumulate at the surface of the sample and so does not act as a protective layer to the thermal and mass transfer. Kashiwagi et al. works also reported that the fire behavior of PMMA/silica composites can be affected by the silica surface area and the PMMA molar mass [19]. Indeed, the most viscous composite, which is made of $10 \mathrm{wt} \%$ of silica gel with large surface area $\left(400 \mathrm{~m}^{2} / \mathrm{g}\right)$ introduced in a high molar mass PMMA $(996000 \mathrm{~g} / \mathrm{mol})$, leads to the best fire performances, because of the decrease of the bubbling compared to less viscous composites. This less vigorous bubbling allows a faster accumulation of the silica near the surface of the material to create the protective layer which is able to improve the fire properties of PMMA.

Given these results, the rheological properties of our PBT composites were studied (Fig. 9) and compared with cone calorimeter results (Table 4 ).

The linear viscoelastic behavior of composites can allow characterizing their morphology [52,53]. In this study we have focused our discussion on the absolute complex viscosity $\left|\eta^{*}(\omega)\right|$ and the storage modulus $\mathrm{G}^{\prime}(\omega)$ obtained at $240{ }^{\circ} \mathrm{C}$. Fig. 9 (a) shows that the neat PBT presents a Newtonian behavior over all the measured frequency range, with a $\left|\eta^{*}\right|$ value equal to 280 Pa s approximately. When silicas are introduced in PBT, the viscosity at low angular frequency of the polyester is increased. The highest viscosity is obtained for PBT/modified silica composites, whose $\left|\eta^{*}\right|$ at low angular frequency is approximately one order of magnitude higher than those of PBT-Z-10\% $\left(\left|\eta^{*}\right|=5.0 \times 10^{3} \mathrm{~Pa} \mathrm{~s}\right)$. The same phenomenon is highlighted for the storage modulus (Fig. 9 (b)). $G^{\prime}$ of all composites reveals the presence of a secondary plateau at low angular frequency, which is characteristic of the presence of a filler network into PBT. The silica treatment by PA, DHAP and DAP leads to an important increase of $\mathrm{G}^{\prime}$ at low angular frequency (also named $\mathrm{G}_{0}$ ) compared to PBT-Z-10\%. Indeed, $\mathrm{G}_{0}$ of PBT-ZmPA-10\%, PBTZmDHAP-10\% and PBT-ZmDAP-10\% are respectively $7.9 \times 10^{3} \mathrm{~Pa}$, $5.8 \times 10^{3} \mathrm{~Pa}$ and $3.8 \times 10^{3} \mathrm{~Pa}$ whereas that of PBT-Z-10\% is $10^{2} \mathrm{~Pa}$. The PBT/modified silica composites exhibit a higher elastic component than PBT-Z-10\%, indicating that inter-particles interactions at submicron scale are increased by the phosphorous compounds. It should be noticed that the amount of ammonium contained in PBT/modified silica composites seems to affect those interactions, since the higher the ammonium content, the lower $\mathrm{G}_{0}$ is.

As said above, the correlation between sample viscosity and cone calorimeter results (Table 4) is examined by using the representation proposed by Batistella et al. [47] in order to reveal the influence of rheological properties on the fire behavior. Thus, the reduced $p H R R$ was plotted versus the reduced viscosity $\left|\eta^{*}\right|$ for each PBT samples. Viscosity measurements were recorded at $240{ }^{\circ} \mathrm{C}$ and $\left|\eta^{*}\right|$ values were taken at low angular frequency, that is to say $2.51 \times 10^{-2} \mathrm{rad} / \mathrm{s}$. Even if these conditions are different from those observed during burning using a cone calorimeter, where a temperature gradient and a viscosity gradient exist, we suppose that the hierarchy of rheological behavior are similar in both cases. As illustrated in Fig. 10, the reduced pHRR decreases linearly with the logarithm of the reduced viscosity. The best fire behavior is obtained for PBT-ZmPA-10\%, which is the most viscous composite at low angular frequency $\left(\left|\eta^{*}\right|=3.3 \times 10^{5} \mathrm{~Pa} \mathrm{~s}\right)$, probably due to the specific dispersion of ZmPA into PBT (formation of a strong network). We already observed a similar trend when using silicas in polypropylene [29]. However an opposite effect of phosphorous surface agents on viscosity was highlighted since the PP/modified silica composites exhibit a lower viscosity than the PP/neat silica.

As reported in the literature $[18,19,47]$ the relative decrease of pHRR can be related to the physical barrier effect in the condensed phase during the burning of materials. Indeed, as discussed above, we believe that viscosity can not only have an influence on the intumescence of the residue and the formation of a protective layer near the surface of the sample but can also have an effect on thermal transfer by modifying the bubbling rate. Therefore we suggest that viscosity and more generally the viscoelastic behavior are the main factor responsible for the improvement of the fire retardancy of PBT.

\section{Conclusions}

The effect of pure and phosphorus modified silica on the fire behavior of PBT composites was investigated. It was highlighted that the introduction of fillers does not change the thermal stability of the PBT under inert or oxidative atmosphere. It was shown that 


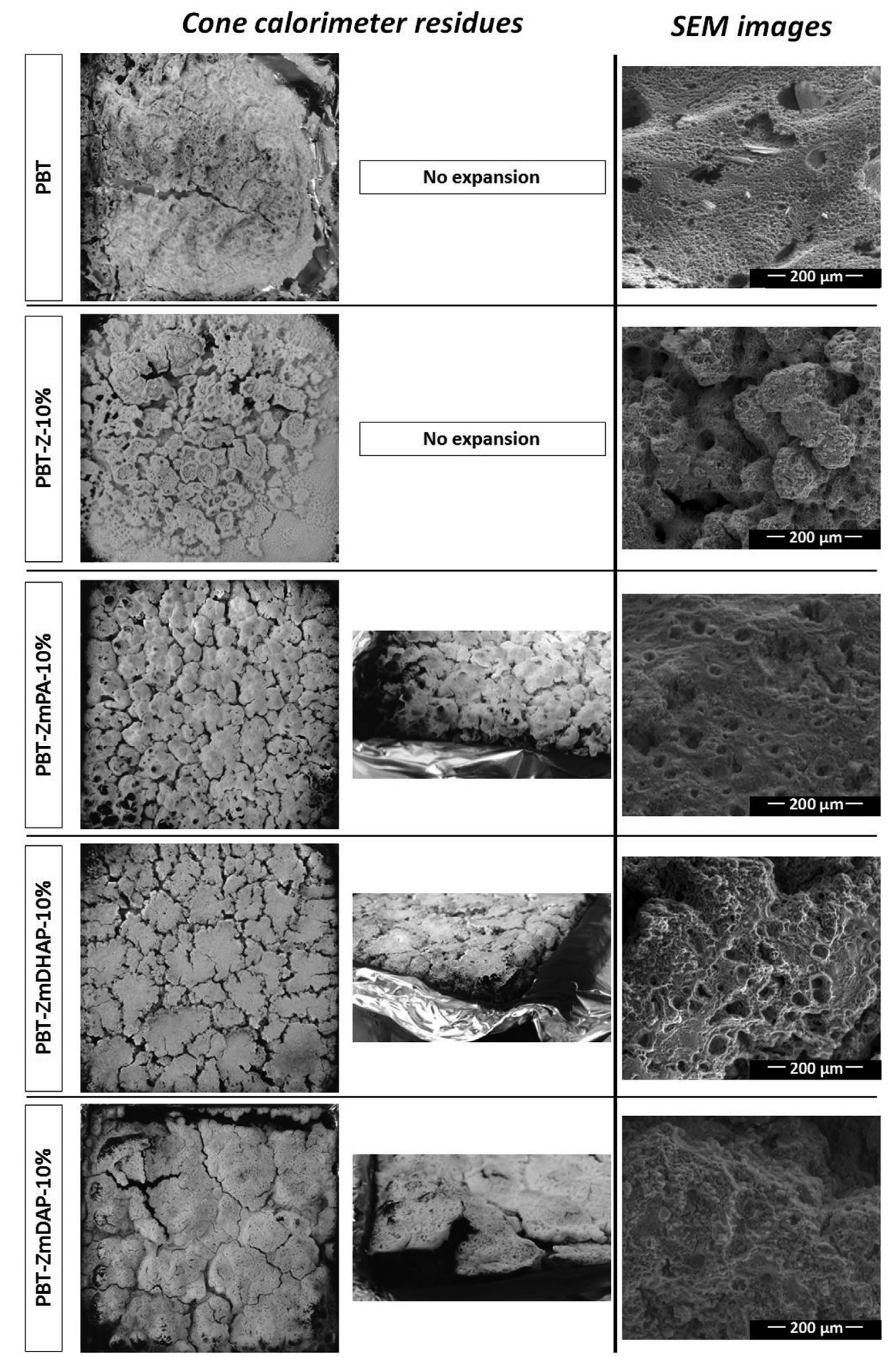

Fig. 8. Cone calorimeter residues and corresponding SEM micrographs for PBT and PBT composites containing silica Z and modified silica ZmPA, ZmDHAP and ZmDAP.

the modification of silica by PA, DHAP and DAP leads to better fire properties in cone calorimeter tests. The small amount of phosphorus in composites (about $0.2 \mathrm{wt} \%$ ) allows the improvement of the barrier effect in the condensed phase which leads to an important reduction of pHRR, i.e. a $54 \%$ decrease in cone calorimeter test. This improvement was related to the expansion of the residue during combustion monitored by the viscosity increase when silica is modified by the three phosphorous RF agents. The higher the viscosity at low angular frequency is, the better the fire properties of PBT are. Indeed, the most viscous composite, PBTZmPA-10\% (at low angular frequency $\left|\eta^{*}\right|=3.3 \times 10^{5} \mathrm{~Pa} \mathrm{~s}$ ) exhibits the smallest fire growth indexes $\left(4.3\right.$ and $9.4 \mathrm{~kW} / \mathrm{m}^{2}$.s 

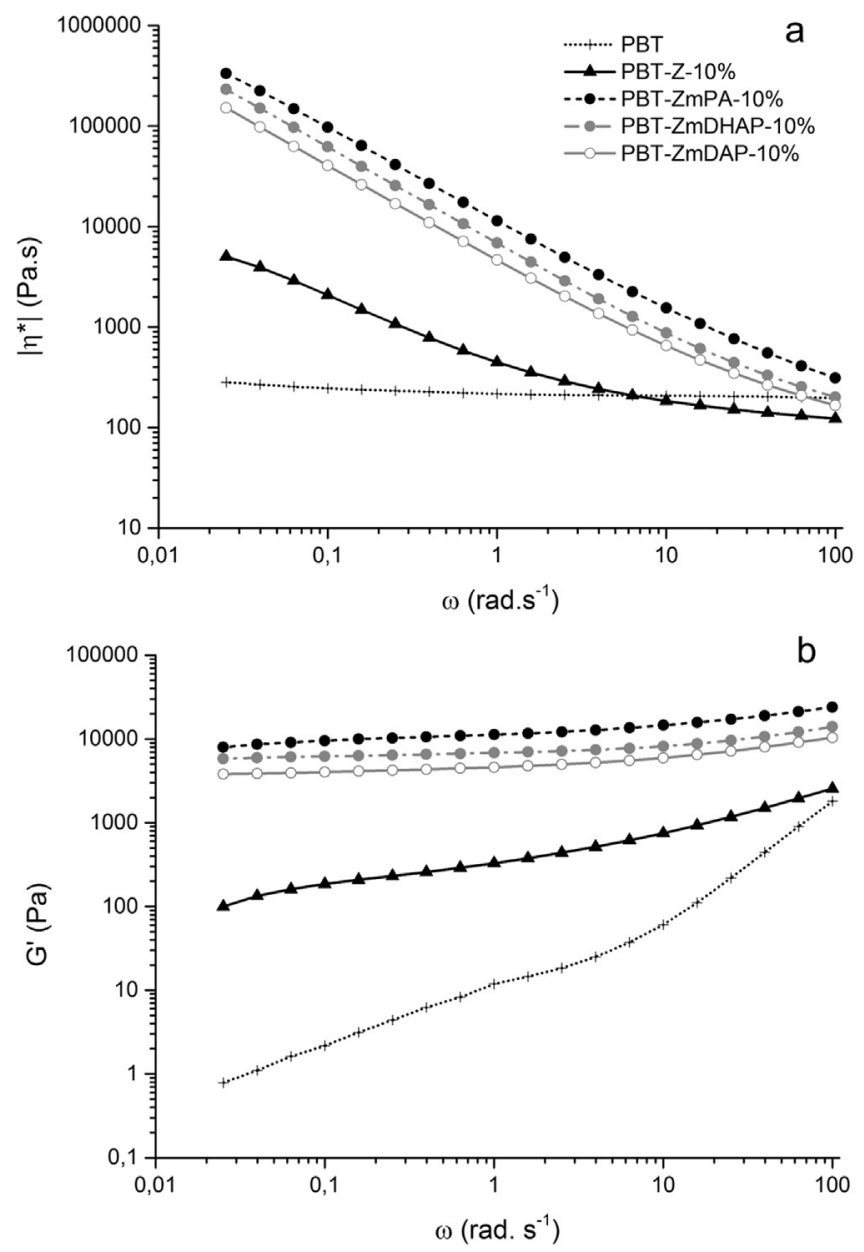

Fig. 9. Variation of (a) complex viscosity and (b) storage modulus for PBT and PBT composites containing silica $\mathrm{Z}$ and modified silica $\mathrm{ZmPA}, \mathrm{ZmDHAP}$ and $\mathrm{ZmDAP}$.

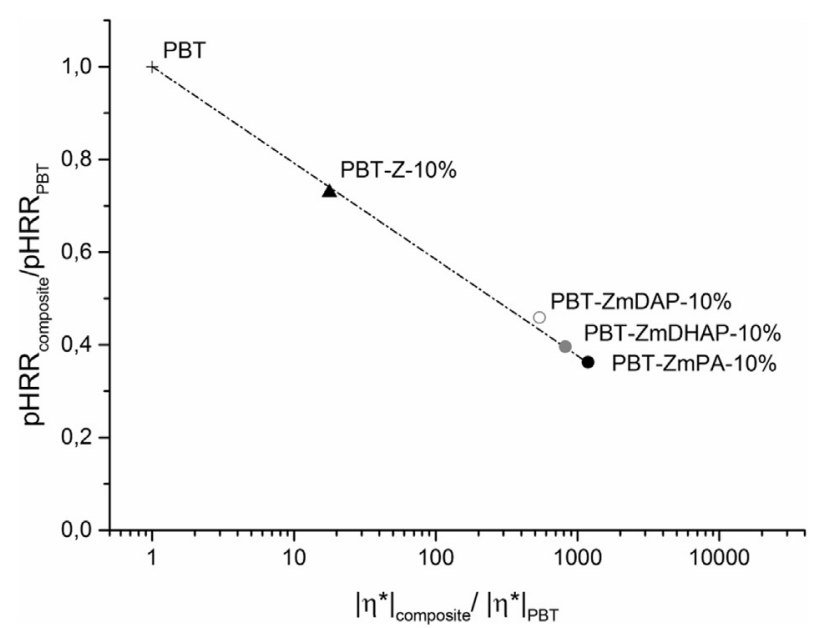

Fig. 10. Variation of reduced PHRR as a function of reduced viscosity at low frequency for PBT and PBT composites containing silica $\mathrm{Z}$ and modified silica ZmPA, ZmDHAP and ZmDAP.

respectively for FIGRA and pHRR/TTI) as well as the lowest pHRR that shows a $60 \%$ decrease compared to neat PBT. Indeed, a high viscosity seems to lead to a decrease of thermal and gas transfer between the flame and the material, thanks to the bubbling limitation, the expansion of the combustion residue and the formation of a protective layer of fillers near the surface of the sample. We have also found that bubbling could affect TTI. The composites showing the greatest bubbling activity after melting exhibit also the lowest TTI. This was attributed to the limitation of heat transfer in the presence of bubbles.

\section{Acknowledgments}

We thank the Region Rhône Alpes (France) and the University of Lyon (France) for financial support FUI SYRIMAP.

\section{References}

[1] J. Green, J. Chung, Flame retarding polybutylene terephthalate - properties, processing characteristics, and rheology, J. Fire Sci. 8 (1990) 254-265.

[2] E.D. Weil, S.V. Levchik, Commercial flame retardancy of thermoplastic polyesters - a review, J. Fire Sci. 22 (2004) 339-350.

[3] G.F. Levchik, Y.V. Grigoriev, A.I. Balabanovich, S.V. Levchik, M. Klatt, Phosphorus-nitrogen containing fire retardants for poly(butylene terephthalate), Polym. Int. 49 (2000) 1095-1100.

[4] S.V. Levchik, D.A. Bright, G.R. Alessio, S. Dashevsky, Synergistic action between aryl phosphates and phenolic resin in PBT, Polym. Degrad. Stab. 77 (2002) $267-272$.

[5] A.I. Balabanovich, Poly(butylene terephthalate) fire retarded by bisphenol a bis(diphenyl phosphate), J. Anal. Appl. Pyrolysis 72 (2004) 229-233.

[6] J. Xiao, Y. Hu, L. Yang, Y. Cai, L. Song, Z. Chen, W. Fan, Fire retardant synergism between melamine and triphenyl phosphate in poly(butylene terephthalate), Polym. Degrad. Stab. 91 (2006) 2093-2100.

[7] A.I. Balabanovich, The effect of melamine on the combustion and thermal decomposition behaviour of poly(butylene terephthalate), Polym. Degrad. Stab. 84 (2004) 451-458.

[8] A.I. Balabanovich, T.A. Zevaco, W. Schnabel, Fire retardance in poly(butylene terephthalate). the effects of red phosphorus and radiation-induced crosslinks, Macromol. Mater. Eng. 289 (2004) 181-190.

[9] F. Gao, L. Tong, Z. Fang, Effect of a novel phosphorous-nitrogen containing intumescent flame retardant on the fire retardancy and the thermal behaviour of poly(butylene terephthalate), Polym. Degrad. Stab. 91 (2006) 1295-1299.

[10] A.I. Balabanovich, A.M. Balabanovich, J. Engelmann, Intumescence in poly(butylene terephthalate): the effect of 2-methyl-1,2-oxaphospholan-5-one 2oxide and ammonium polyphosphate, Polym. Int. 52 (2003) 1309-1314.

[11] S. Brehme, B. Schartel, J. Goebbels, O. Fischer, D. Pospiech, Y. Bykov, M. Döring, Phosphorus polyester versus aluminium phosphinate in poly(butylene terephthalate) (PBT): flame retardancy performance and mechanisms, Polym. Degrad. Stab. 96 (2011) 875-884.

[12] U. Braun, H. Bahr, H. Sturm, B. Schartel, Flame retardancy mechanisms of metal phosphinates and metal phosphinates in combination with melamine cyanurate in glass-fiber reinforced poly(1,4-butylene terephthalate): the influence of metal cation, Polym. Adv. Technol. 19 (2008) 680-692.

[13] U. Braun, B. Schartel, Flame retardancy mechanisms of aluminium phosphinate in combination with melamine cyanurate in glass-fibre-reinforced poly(1,4-butylene terephthalate), Macromol. Mater. Eng. 293 (2008) 206-217.

[14] S. Sullalti, M. Colonna, C. Berti, M. Fiorini, S. Karanam, Effect of phosphorus based flame retardants on UL94 and Comparative Tracking Index properties of poly(butylene terephthalate), Polym. Degrad. Stab. 97 (2012) 566-572.

[15] A. Ramani, A.E. Dahoe, On the performance and mechanism of brominated and halogen free flame retardants in formulations of glass fibre reinforced poly(butylene terephthalate), Polym. Degrad. Stab. 104 (2014) 71-86.

[16] E. Gallo, U. Braun, B. Schartel, P. Russo, D. Acierno, Halogen-free flame retarded poly(butylene terephthalate) (PBT) using metal oxides/PBT nanocomposites in combination with aluminium phosphinate, Polym. Degrad. Stab. 94 (2009) 1245-1253.

[17] J.W. Gilman, T. Kashiwagi, M. Nyden, R.H. Harris Jr., NISTIR 6357 New Flame Retardants Consortium: Final Report - Flame Retardant Mechanism of Silica, 1999.

[18] T. Kashiwagi, J.W. Gilman, K.M. Butler, R.H. Harris, J.R. Shields, A. Asano, Flame retardant mechanism of silica gel/silica, Fire Mater 24 (2000) 277-289.

[19] T. Kashiwagi, J.R. Shields, R.H. Harris, R.D. Davis, Flame-retardant mechanism of silica: effects of resin molecular weight, J. Appl. Polym. Sci. 87 (2003) $1541-1553$.

[20] Z. Fanglong, X. Qun, F. Qianqian, L. Rangtong, L. Kejing, Influence of nano-silica on flame resistance behavior of intumescent flame retardant cellulosic textiles: remarkable synergistic effect? Surf. Coatings Technol. 294 (2016) 90-94.

[21] Z.-H. Wu, J.-P. Qu, Y.-Q. Zhao, H.-L. Tang, J.-S. Wen, Flammable and mechanical effects of silica on intumescent flame retardant/ethylene-octene copolymer/ polypropylene composites, J. Thermoplast. Compos. Mater 28 (2015) 981-994.

[22] X. Chen, Y. Jiang, J. Liu, C. Jiao, Y. Qian, S. Li, Smoke suppression properties of fumed silica on flame-retardant thermoplastic polyurethane based on 
ammonium polyphosphate, J. Therm. Anal. Calorim. 120 (2015) 1493-1501.

[23] J. Alongi, C. Colleoni, G. Rosace, G. Malucelli, Sol-gel derived architectures for enhancing cotton flame retardancy: effect of pure and phosphorus-doped silica phases, Polym. Degrad. Stab. 99 (2014) 92-98.

[24] P. Theil-Van Nieuwenhuyse, V. Bounor-Legaré, P. Bardollet, P. Cassagnau, A. Michel, L. David, F. Babonneau, G. Camino, Phosphorylated silica/polyamide 6 nanocomposites synthesis by in situ sol-gel method in molten conditions: impact on the fire-retardancy, Polym. Degrad. Stab. 98 (2013) 2635-2644.

[25] J. Sahyoun, V. Bounor-Legaré, L. Ferry, R. Sonnier, A. Bonhommé, P. Cassagnau, Influence of organophosphorous silica precursor on the thermal and fire behaviour of a PA66/PA6 copolymer, Polym. Degrad. Stab. 115 (2015) 117-128.

[26] J. Sahyoun, V. Bounor-Legaré, L. Ferry, R. Sonnier, F. Da Cruz-Boisson, F. Melis, A. Bonhommé, P. Cassagnau, Synthesis of a new organophosphorous alkoxysilane precursor and its effect on the thermal and fire behavior of a PA66/PA6 copolymer, Eur. Polym. J. 66 (2015) 352-366.

[27] Q. Dong, Y. Ding, B. Wen, F. Wang, H. Dong, S. Zhang, T. Wang, M. Yang, Improvement of thermal stability of polypropylene using DOPO-immobilized silica nanoparticles, Colloid Polym. Sci. 290 (2012) 1371-1380.

[28] O. Dong, M. Liu, Y. Ding, F. Wang, C. Gao, P. Liu, B. Wen, S. Zhang, M. Yang, Synergistic effect of DOPO immobilized silica nanoparticles in the intumescent flame retarded polypropylene composites, Polym. Adv. Technol. 24 (2013) 732-739.

[29] J. Courtat, F. Melis, J.-M. Taulemesse, V. Bounor-Legare, R. Sonnier, L. Ferry, P. Cassagnau, Effect of phosphorous-modified silica on the flame retardancy of polypropylene based nanocomposites, Polym. Degrad. Stab. 119 (2015) 260-274.

[30] G. Dorez, A. Taguet, L. Ferry, J.M. Lopez Cuesta, Phosphorous compounds as flame retardants for polybutylene succinate/flax biocomposite: additive versus reactive route, Polym. Degrad. Stab. 102 (2014) 152-159.

[31] C. Huggett, Estimation of rate of heat release by means of oxygen consumption measurements, Fire Mater 4 (1980) 61-65.

[32] B. Schartel, T.R. Hull, Development of fire-retarded materials-interpretation of cone calorimeter data, Fire Mater 31 (2007) 327-354.

[33] E. Gallo, G. Sánchez-Olivares, B. Schartel, Flame retardancy of starch-based biocomposites - aluminum hydroxide-coconut fiber synergy, Polimery/Polymers 58 (2013) 395-402.

[34] F. Carniato, G. Paul, C. Bisio, S. Caldarelli, L. Marchese, On the organic/inorganic interface between mesoporous SBA-16 silica and its structural directing polymer: a combined FT-IR and solid state NMR study, RSC Adv. 2 (2012) 1153.

[35] K.K. Unger, Chapter 1 general chemistry of silica, in: J. Chromatogr. Libr., 1979: pp. $1-14$.

[36] A.I. Balabanovich, J. Engelmann, Fire retardant and charring effect of poly(sulfonyldiphenylene phenylphosphonate) in poly(butylene terephthalate), Polym. Degrad. Stab. 79 (2003) 85-92.

[37] T. Arii, Y. Masuda, The effect of humidity on thermal decomposition of terephthalate polyester, J. Anal. Appl. Pyrolysis 71 (2004) 525-536.

[38] S. Nazare, T.R. Hull, B. Biwas, F. Samyn, S. Bourbigot, C. Jama, A. Castovinci, A. Fina, G. Camino, Study of the relationship between flammability and melt rheological properties of flame-retarded poly(butylene terephthalate) containing nanoclays, in: T.R. Hull, B. Kandola (Eds.), Fire Retard. Polym. New
Strateg. Mech, RSC Publishing, Cambridge, 2008, pp. 168-183.

39] A. Massa, A. Scettri, S. Contessa, V. Bugatti, S. Concilio, P. Iannelli, New catalyst for the synthesis of poly(butylene terephthalate) with high thermo-oxidative stability, J. Appl. Polym. Sci. 104 (2007) 3071-3076.

[40] J. Bian, H.L. Lin, F.X. He, L. Wang, X.W. Wei, I.T. Chang, E. Sancaktar, Processing and assessment of high-performance poly(butylene terephthalate) nanocomposites reinforced with microwave exfoliated graphite oxide nanosheets, Eur. Polym. J. 49 (2013) 1406-1423.

[41] W. Yang, Y. Hu, Q. Tai, H. Lu, L. Song, R.K.K. Yuen, Fire and mechanical performance of nanoclay reinforced glass-fiber/PBT composites containing aluminum hypophosphite particles, Compos. Part A Appl. Sci. Manuf. 42 (2011) 794-800.

[42] R.E. Lyon, J.G. Quintiere, Criteria for piloted ignition of combustible solids, Combust. Flame 151 (2007) 551-559.

[43] E.S. Oztekin, S.B. Crowley, R.E. Lyon, S.I. Stoliarov, P. Patel, T.R. Hull, Sources of variability in fire test data: a case study on poly(aryl ether ether ketone) (PEEK), Combust. Flame 159 (2012) 1720-1731.

[44] A. Fina, J. Feng, F. Cuttica, In-depth radiative heat transmittance through polypropylene/nanoclay composites, Polym. Degrad. Stab. 98 (2013) 1030-1035.

[45] R. Sonnier, L. Ferry, C. Longuet, F. Laoutid, B. Friederich, A. Laachachi, J.M. Lopez-Cuesta, Combining cone calorimeter and PCFC to determine the mode of action of flame-retardant additives, Polym. Adv. Technol. 22 (2011) 1091-1099.

[46] R. Sonnier, B. Otazaghine, L. Ferry, J.M. Lopez-Cuesta, Study of the combustion efficiency of polymers using a pyrolysis-combustion flow calorimeter Combust. Flame 160 (2013) 2182-2193.

[47] M. Batistella, B. Otazaghine, R. Sonnier, A.S. Caro-Bretelle, C. Petter, J.M. Lopez Cuesta, Fire retardancy of ethylene vinyl acetate/ultrafine kaolinite composites, Polym. Degrad. Stab. 100 (2014) 54-62.

[48] W. Yang, L. Song, Y. Hu, H. Lu, R.K.K.Y. Yuen, Investigations of thermal degradation behavior and fire performance of halogen-free flame retardant poly(1,4-butylene terephthalate) composites, J. Appl. Polym. Sci. 122 (2011) $1480-1488$.

[49] L. Clerc, L. Ferry, E. Leroy, J.M. Lopez-Cuesta, Influence of talc physical properties on the fire retarding behaviour of (ethylene-vinyl acetate copolymer magnesium hydroxide/talc) composites, Polym. Degrad. Stab. 88 (2005) 504-511.

[50] T. Kashiwagi, M. Mu, K. Winey, B. Cipriano, S.R. Raghavan, S. Pack, M. Rafailovich, Y. Yang, E. Grulke, J. Shields, R. Harris, J. Douglas, Relation between the viscoelastic and flammability properties of polymer nanocomposites, Polym. Guildf. 49 (2008) 4358-4368.

[51] T. Kashiwagi, F. Du, J.F. Douglas, K.I. Winey, R.H. Harris, J.R. Shields, Nanoparticle networks reduce the flammability of polymer nanocomposites, Nat. Mater 4 (2005) 928-933, http://dx.doi.org/10.1038/nmat1502.

[52] P. Cassagnau, Melt rheology of organoclay and fumed silica nanocomposites, Polym. Guildf. 49 (2008) 2183-2196.

[53] C. Bartholome, E. Beyou, E. Bourgeat-Lami, P. Cassagnau, P. Chaumont, L. David, N. Zydowicz, Viscoelastic properties and morphological characterization of silica/polystyrene nanocomposites synthesized by nitroxidemediated polymerization, Polym. Guildf. 46 (2005) 9965-9973. 